\title{
Why Residents of South China live longer than those of North China?
}

yi huang ( $\square$ huangyi@ntu.edu.cn)

Nantong University

Mengqi Wang

Nantong University

Yanxin Song

Nantong University

Shuangping Zhang

Nantong University

\section{Research article}

Keywords: Mortality rate; North China; South China; Life expectancy; Longevity; CVD

Posted Date: November 26th, 2019

DOI: https://doi.org/10.21203/rs.2.17818/v1

License: (a) (i) This work is licensed under a Creative Commons Attribution 4.0 International License. Read Full License 


\section{Abstract}

Background, Since 1990, life expectancy and nonagenarian ratio in South China have been higher than those in North China. Methods, To determine the reason residents of South China live longer, we calculated age-specific mortality rates (per 100,000 people) in North and South China. We examined the associations between the provincial mortality rates due to major fatal diseases and life span indicator. Results, CVD is the leading cause of death in China. The proportion of CVD in all-cause mortality increases with age, and its mortality rate accounts for over $50 \%$ of all-cause mortalities in people aged over 80 years. Moreover, the mortality rate of CVD gradually decreases from north to south, indicating the main reason of difference in longevity between North and South China. This difference can be attributed to variations in temperature, salt consumption, selenium intake, air pollution, overweight and obesity between the two regions. Lower mortality rates of individuals aged 55-89 years in South China lead to higher longevity level. Provincial gravity centers of the proportion of longevity population move southward, and this shift is accelerated with increasing age. Conclusions, the mortality rate of CVD gradually decreases from north to south is the reason residents of South China live longer, and risk factors of CVD gradually decreases from north to south.

\section{Background}

Life expectancy at birth (defined as the mean number of years remaining at birth until death under specific mortality conditions) and longevity ratio (defined as the ratio of the population above 90 years of age) are currently the main and commonly used lifespan indicators to determine the longevity level1,2,3,4,5.

Beijing and Shanghai are the two largest and most developed cities in China, located in North and South China, respectively. Beijing and Shanghai possess the best medical universities, the most advanced hospitals, the most substantial medical conditions, and the highest population health literacy of China. According to the population census data in 1990, 2000, and 2010, Shanghai ranked first, whereas Beijing ranked second in China in terms of life expectancy. Furthermore, Beijing has a far lower nonagenarian ratio than Shanghai. Since 1990, North China has consistently showed lower life expectancy and considerably lower longevity ratio than South China (Table 1). Of note, Mainland China has 31 provinces. South and North China each contain 15 provinces. Meanwhile, Tibet is included in neither North nor South China because although Tibet is geographically located in the south, the average elevation is over $4500 \mathrm{~m}$, and its temperature, atmospheric pressure, and oxygen content are far lower than those of other provinces.

Table 1 presents the life expectancy and longevity ratio in Shanghai-both ranked first-as well as in Beijing-with longevity ratio merely ranked middle among 31 provinces in China. Why residents of Shanghai far easily live for over 90 years of age compared with those of Beijing?

\section{Methods}

\section{Association between age-specific mortality and longevity}

To know why residents in North China do not live as long as those in South China, we calculated age-specific mortality per 100,000 people in North and South China. The results are illustrated in Fig. 1. The number of deaths in the population aged 55-89 years was significantly lower in Shanghai than in Beijing. Meanwhile, the number of deaths in the population aged 55-89 years was significantly lower in South China than in North China, whereas the numbers of deaths in the populations aged 0-55 years and 90-100 years were almost the same. In general, a lower mortality rate of the population aged 55-89 years in Shanghai and South China led to a greater proportion of older population. A few years later, some of them will become nonagenarians or even centenarians. Hence, Beijing showed a slightly lower life expectancy and a considerably lower proportion of longevity population than Shanghai.

High medical security in Beijing reduced the mortality rate of younger population, providing an important support for the highest life expectancy. However, the mortality rate of people aged 55-89 years was generally 50-150 times higher than that of people aged under 35 years, indicating that the population aged 55-89 years experienced the highest number of deaths (Fig. 1). If the mortality rate of people aged 55-89 years decreases slightly, many people will live to over 90 years and the longevity ratio will sharply increase in a short term.

Therefore, considering that the mortality rate of people aged 55-89 years in Beijing is higher than that in Shanghai, the proportion of people over 90 years of age in Beijing is considerably lower than that in Shanghai. The same trend applies to North and South China.

\section{Results}

\section{Age-standardized rates of four major fatal diseases between North and South China}

To study the reason underlying differences in longevity between North and South China, we selected the mortality rate of major fatal diseases, according to the statistical data of leading mortality causes in China6. CVD, tumors, and respiratory diseases were the three leading causes of death in both rural and urban populations in China. Of all deaths in rural and urban areas, CVD-related deaths accounted for $45.50 \%$ and $43.16 \%$, followed by tumor-related deaths at $22.92 \%$ and $26.06 \%$ and respiratory disease-related deaths at $12.02 \%$ and $11.24 \%$, respectively. Overall, the three diseases accounted for $80.44 \%$ and $80.46 \%$ of all deaths in rural and urban areas, respectively. Moreover, the contribution of CVD and respiratory diseases to all-cause mortality rate increased with age but that of tumors decreased with age (Table 2).

CVD can be further divided into cerebrovascular and heart diseases. To compare the mortality rates of the four major diseases between North and South China, we collected and mapped the provincial mortality rate data 78 (Fig. 2). Comparisons between North and South China as well as between Beijing and Shanghai are presented in Table 3.

\section{Discussion}


As illustrated in Table 3, expect those of cerebrovascular disease and heart disease, the mortality rates of all other reasons in Shanghai and South China were higher than those in Beijing and North China, respectively. Thus, the difference of CVD mortality rates is the fundamental reason for the difference of the longevity level between North and South China.

To evaluate the correlations among the four major diseases and nonagenarian ratio, we generated a Spearman's rank correlation matrix (Table 4). The correlation coefficients between the nonagenarian ratio and CVD were significant and negative, whereas the correlation coefficients between the nonagenarian ratio and illnesses such as cancer and respiratory diseases were not significant.

Based on this matrix, we conducted correlation and principal component analyses to determine the associations of the nonagenarian ratio with the major diseases (Table 5). The order in which factors were interpreted was determined based on the magnitude of their eigenvalues. In Table 5, the eigenvalues of the first factor (F1) are considerably higher than those of F2 and F3, and F1 showed a high positive loading for CVD.

The proportion of nonagenarians in northern provinces was significantly lower than that in southern provinces (Table 1), possibly due to the significant and positive correlation with CVD. Fig. 2 and Table 3 illustrate that among the four major diseases, cancer is randomly distributed in China. Additionally, the mortality rate of respiratory diseases in South China is generally higher than that in North China. Conversely, the mortality rate of CVD in South China is generally lower than that in North China, which is consistent with other studies 9: Nine provinces in North China, namely Heilongjiang, Jilin, Liaoning, Inner Mongolia, Hebei, Beijing, Ningxia, Tibet, and Xinjiang, have a high incidence of stroke, constituting a stroke belt in China. The stroke incidence in the stroke zone was 236.2/100,000, which was significantly higher than that in the areas outside the stroke zone $(109.7 / 100,000)$. Considering that the mortality rate of CVD is considerably higher than that of respiratory diseases, a lower mortality rate of CVD in South China led to higher life expectancy and longevity ratio.

Based on the 2010 national census data for China, the provincial gravity center evolution map for the proportion of population from over 65 years to over 100 years was drawn (Fig. 3).

Fig. 3 shows that the provincial gravity centers of the proportion of aging population and longevity population move southward as the age increases, and this shift does not reverse. As the age increases, the gravity centers of the proportion of aging population in China move along the same path as that of the gravity centers of the lowest temperature during winter. The speed is gradually accelerating southward, as illustrated in Table 6.

According to CVD reports in China in 2015, 2016, 2017, and 201810, some influencing factors for CVD (e.g., temperature, salt consumption, selenium intake, air pollution, overweight, and obesity) may present north-south differences.

High sodium intake is internationally recognized as the main cause of hypertension. In fact, $25.2 \%$ of the CVD deaths can be attributed to high-sodium diets, ranking first among all diseases; the disease burden attributable to high-sodium diets in North China is considerably more serious than that in South China; the top 10 provinces with high disease burden due to high-sodium diets were all located in the north11.

Extreme temperatures have a significant impact on mortality in elderly people12. The associations of high and low temperature with death differ, and more cold-related deaths have been reported than heat-related deaths13. Furthermore, the effects of low temperatures may persist for several days 14 , whereas those of high temperatures are restricted to the day of the death or to the next day for all CVD cases; the hot-day effect was five times less severe than the cold-day effect 15 . In Shenzhen, there was a significant increase in CVD mortality rate over low-temperature days compared with that over high-temperature days16. North China is considerably colder than South China during winter, possibly leading to higher CVD mortality rate. However, in summer, North China also faces heat waves.

In medical cases and clinical reports of 133,957 people, selenium intake was negatively correlated with CVD mortality risk in males and females 17 , and the distribution of selenium in the soil of China gradually increases from north to south18. Furthermore, air pollution is becoming a threat to public health. In several studies, PM2.5, SO2, and NO2 were positively correlated with hypertension and CVD, and PM10 and PM2.5 gradually decrease from north to south in China. The government provides free or heavily subsidized coal for indoor heating during the winter to cities north of the Huai River but not to those in the south; excess coal burning pollutes the air in the north; furthermore, the short lifespans are almost entirely caused by elevated rates of CVD mortality $19,20$.

In addition, obesity and overweight are two of the most common causes of CVD. These are highly prevalent in north and northeastern areas of China21. A report on risk factor surveillance of chronic disease in China also showed that obesity and overweight are more prevalent in North China than in South China, and top one-third provinces with high obesity and overweight rate are all located in the north22.

\section{Conclusion}

1. Lower mortality rates of individuals aged 55-89 years in South China lead to higher longevity

2. Mortality rate of CVD accounts for over $50 \%$ of all-cause mortalities in people aged over 80 years, expect those of cerebrovascular disease and heart disease, the mortality rates of all other reasons in South China were higher than those in North 3

3. The mortality rate of CVD and its risk factors gradually decreases from north to south.

4. Provincial gravity centers of the proportion of longevity population move southward, and this shift is accelerated with increasing age.

\section{Abbreviations}

CVD: Cerebrovascular disease and heart disease. 


\section{Declarations}

Ethics approval and consent to participate: Not required

Consent for publication: consent for publication was obtained from all participants. Availability of data and materials: the Fifth and Sixth National population census; 2017 Year book of health and family planning in the People's Republic of China; Report on cardiovascular diseases in China 2017, China Death Cause Surveillance Data Set 2013; Report on Chinese Residents' Chronic Disease and Nutrition 2015.

Competing interests: None declared

Funding: This work was supported by the National Natural Sciences Foundation of Jiangsu Province [grant number BK20150405]; National Natural Sciences Foundation of Nantong City [grant number JC2018078]; and the Key Laboratory Foundation of Nantong City [grant number CP12016005]. These funding provide fee for data collection in research and publish fee.

Authors' contributions: Yi Huang designed the experiment, Yi Huang wrote the paper, Mengqi Wang, Shuangping Zhang and Yanxin Song collected the data. All authors have read and approved the manuscript.

Acknowledgements: Not applicable.

\section{References}

1. Magnolfi S, Petruzzi E, Pinzani P, et al. Longevity index (LI\%) and centenarity index (Cl\%):New indicators to evaluate the characteristics of aging process in the Italian population. Archives of Gerontology and Geriatrics 2007;44:271-6.

2. Li Wang, Binggan Wei, Yonghua Li, et al. A study of air pollutants influencing life expectancy and longevity from spatial perspective in Science of the Total Environment 2014;487:57-64.

3. Wenjin Song, Yonghua Li, Zhe Hao, et al. Public health in China: an environmental and socio- economic perspective. Atmospheric Environment 2016;129:9-17.

4. Yuan Liu, Yonghua Li, Yu Jiang, et Effects of Soil Trace Elements on Longevity Population in China. Biological Trace Element Research 2013;153:11926.

5. Weixia Sun, Biao Huang, Yongcun Zhao, et al. Spatial variability of soil selenium as affected by geologic and pedogenic processes and its effect on ecosystem and human health. Geochemical Journal 2009;43:217-25.

6. National Health and Family Planning Commission of People's Republic of China. 2017 Year book of health and family planning in the People's Republic of

7. Chinese Center for Disease Control and Prevention. China Death Cause Surveillance Data Set 2013.

8. Report on Chinese Residents' Chronic Disease and Nutrition 2015, People's Medicine Publishing House.

9. Xu Gelin, Ma Minmin, Liu Xinfeng. Is there a stroke belt in China and why? Stroke 2013;44:1775-83.

10. National Center for Cardiovascular Diseases, Report on cardiovascular diseases in China 2017.

11. Liu Min, Li Yichong, Liu Burden of disease attributable to high- sodium diets in China. Chinese Journal of Preventive Medicine 2016;50:759-63. [in Chinese with English abstract]

12. Dimitriou K, McGregor G, Kassomenos P, Paschalidou Exploring winter mortality variability in five regions of England, using back trajectory analysis. Earth Interactions 2016;20:1-27.

13. Kalkstein LS, Greene JS. An evaluation of climate/mortality relationship in large ,.S. cities and the possible impacts of a climate change. Environ Health Perspect1997;105:84-93.

14. Zhang Y, Yu C, Peng The burden of ambient temperature on years of life lost: A multi-community analysis in Hubei, China. Sci Total Environ 2018;621:1491-8.

15. Alfésio LF, Antonella Z, Joel S. The effect of weather on respiratory and cardiovascular deaths in 12 ,.S. cities. Environmental Health Perspectives 2002;110:859-6

16. Duan Yanran, Liao Yi, Li Hongyan, et al. Effect of changes in season and temperature on cardiovascular mortality associated with nitrogen dioxide air pollution in Shenzhen, China. The Science of the Total Environment 2019;697:134051.

17. Sun JW, Shu XO, Li HL, et al. dietary selenium intake and mortality in two population-based cohort studies of 133957 Chinese men and women. Public Health Nutr. 2016;19:2991-8.

18. Tan J, Zhu W, Wang W, Hou S, Wang D, Yang Selenium in soil and endemic diseases in China. Sci Total Environ 2002;284:227-35.

19. Chen R, Yin P, Meng X, et al. Fine particulate air pollution and daily mortality: A nationwide analysis in 272 Chinese cities. Am J Respir Crit Care Med 2017;196:73-81.

20. Avraham Ebensteina, Maoyong Fanb, Michael Greenstonec, et al. New evidence on the impact of sustained exposure to air pollution on life expectancy from China's Huai River Policy. PNAS 2017;114:10384-9. https://doi.org/10.1073/pnas.1616784114.

21. Chen Yi-shan, Zhang Yi-min, Kong Zhen-xing, et al. The prevalence of overweight and obesity in children and adolescents in China. Chinese Journal of Disease Control and Prevention 2017;21:866-9. [in Chinese with English abstract] 
22. China Center for Disease Control and Prevention. Report on Chronic Disease Risk Factor surveillance in China 2013. Military Medical Science Press. [in Chinese]

\section{Tables}

Table 1. Life span indicators between Beijing and Shanghai and between North and South China

\begin{tabular}{|c|c|c|c|c|c|c|c|}
\hline & \multicolumn{5}{|c|}{ Life expectancy and ranking } & \multicolumn{2}{|c|}{ Longevity ratio $(90+/ 0+)$} \\
\hline Year & 1990 & 2000 & & 2010 & 2018 & 2000 & 2010 \\
\hline Beijing & $72.9 \quad 2$ & 76.1 & 2 & 80.2 & 282.22 & $0.43 \% 13$ & $1.27 \%$ o 16 \\
\hline Shanghai & $\begin{array}{ll}74.9 & 1\end{array}$ & 78.1 & 1 & 80.3 & 183.61 & $0.79 \%$ о 1 & $2.75 \% \quad 1$ \\
\hline $\begin{array}{l}\text { North } \\
\text { China }\end{array}$ & 68.1 & 71.4 & & 75.0 & - & $0.30 \%$ & $1.03 \%$ о \\
\hline $\begin{array}{l}\text { South } \\
\text { China }\end{array}$ & 68.7 & 71.6 & & 75.2 & - & $0.43 \%$ & $1.67 \%$ \\
\hline China & 68.6 & 71.4 & & 74.8 & 77.0 & $0.39 \%$ & $1.49 \%$ o \\
\hline
\end{tabular}

Columns on the right of life expectancy and longevity ratio is the rank of Beijing and Shanghai

Table 2. Change of mortality rate (per 100000 ) of main diseases and proportion in all-cause mortality with age

\begin{tabular}{lllllllllll}
\hline $\begin{array}{l}\text { Age } \\
\text { (years) }\end{array}$ & \multicolumn{2}{c}{ CVD } & & \multicolumn{2}{c}{ tumors } & \multicolumn{2}{c}{$\begin{array}{l}\text { Respiratory } \\
\text { diseases }\end{array}$} & \multicolumn{2}{c}{ Other diseases } & Non-disease \\
\hline $85+$ & 10441.75 & $55.69 \%$ & 2078.58 & $11.09 \%$ & 3226.86 & $17.21 \%$ & 2365.68 & $12.62 \%$ & 637.62 & $3.40 \%$ \\
\hline $80-84$ & 4061.87 & $52.53 \%$ & 1486.69 & $19.23 \%$ & 1160.37 & $15.01 \%$ & 807.81 & $10.45 \%$ & 215.73 & $2.79 \%$ \\
\hline $75-79$ & 1755.33 & $48.34 \%$ & 926.2 & $25.51 \%$ & 470.45 & $12.96 \%$ & 371.13 & $10.22 \%$ & 107.83 & $2.97 \%$ \\
\hline $70-74$ & 982.77 & $43.89 \%$ & 711.27 & $31.76 \%$ & 238.53 & $10.65 \%$ & 227.74 & $10.17 \%$ & 79.06 & $3.53 \%$ \\
\hline $65-69$ & 613.77 & $39.18 \%$ & 597.36 & $38.14 \%$ & 121.03 & $7.73 \%$ & 160.39 & $10.24 \%$ & 73.83 & $4.71 \%$ \\
\hline
\end{tabular}

Table 3. Age-standardized mortality rates (per 100,000 people) with the leading causes in 2013

\begin{tabular}{|c|c|c|c|c|c|c|c|c|c|c|c|}
\hline & $\begin{array}{l}\text { Cerebrovascul } \\
\text { ar disease }\end{array}$ & $\begin{array}{l}\text { Heart } \\
\text { disease }\end{array}$ & $\begin{array}{l}\text { Respiratory } \\
\text { diseases }\end{array}$ & $\begin{array}{l}\text { Lung } \\
\text { cancer }\end{array}$ & $\begin{array}{l}\text { Liver } \\
\text { cancer }\end{array}$ & $\begin{array}{l}\text { Stomach } \\
\text { cancer }\end{array}$ & \begin{tabular}{l}
\multicolumn{1}{c}{ Colon } \\
and \\
rectum \\
cancer
\end{tabular} & $\begin{array}{l}\text { Total } \\
\text { of four } \\
\text { major } \\
\text { cancers }\end{array}$ & $\begin{array}{l}\text { Total of } \\
\text { four } \\
\text { major } \\
\text { diseases }\end{array}$ & $\begin{array}{l}\text { Mortality } \\
\text { rate }\end{array}$ & $\begin{array}{l}\text { Mortality } \\
\text { rate } \\
\text { without } \\
\text { CVD }\end{array}$ \\
\hline $\begin{array}{l}\text { Males in } \\
\text { Beijing }\end{array}$ & 144.5 & 154.7 & 56.6 & 51.5 & 20.3 & 15.1 & 15.2 & 102.1 & 457.8 & 438.3 & 139.1 \\
\hline $\begin{array}{l}\text { Males in } \\
\text { Shanghai }\end{array}$ & 97.8 & 65.2 & 74.5 & 52.2 & 21.1 & 25.4 & 18.9 & 117.6 & 355.1 & 415.9 & 252.9 \\
\hline $\begin{array}{l}\text { Females in } \\
\text { Beijing }\end{array}$ & 91.7 & 108.6 & 37.1 & 23.4 & 7 & 5.5 & 10.2 & 46.1 & 283.5 & 356.1 & 155.8 \\
\hline $\begin{array}{l}\text { Females } \\
\text { in }\end{array}$ & 79.8 & 49.7 & 35.7 & 17.9 & 8.2 & 11.1 & 13.9 & 51.1 & 216.3 & 331.7 & 202.2 \\
\hline \multicolumn{12}{|l|}{ Shanghai } \\
\hline $\begin{array}{l}\text { Males in the } \\
\text { north }\end{array}$ & 199.84 & 196.6 & 99.18 & 52.6 & 29.2 & 37.2 & 11.35 & 130.4 & 625.9 & 632.4 & 236.0 \\
\hline $\begin{array}{l}\text { Males in the } \\
\text { south }\end{array}$ & 170.88 & $5^{129.8}$ & $5^{143.3}$ & $\begin{array}{l}58.8 \\
3\end{array}$ & $\begin{array}{l}39.7 \\
3 \\
\end{array}$ & $1^{30.1}$ & 14.14 & $1^{142.8}$ & $9^{586.8}$ & 618.4 & 317.7 \\
\hline $\begin{array}{l}\text { Females in } \\
\text { the } \\
\text { north }\end{array}$ & 136.15 & $3^{144.0}$ & 72.21 & $9^{23.1}$ & $\begin{array}{l}2^{12.2} \\
\end{array}$ & $6^{14.5}$ & 7.94 & 57.91 & 410.3 & 509.5 & 229.4 \\
\hline $\begin{array}{l}\text { Females in } \\
\text { the } \\
\text { south }\end{array}$ & 116.28 & 92.19 & 90.68 & $5^{19.0}$ & $9^{12.7}$ & $7^{12.3}$ & 9.39 & 53.6 & $5^{352.7}$ & 458.6 & 250.1 \\
\hline
\end{tabular}


Table 4. Spearman's rank correlation matrix for major diseases and nonagenarian ratio

\begin{tabular}{|c|c|c|c|c|}
\hline & Cerebrovascular disease & Heart disease & Cancer & Respiratory diseases \\
\hline Male & $-0.423^{*}$ & $-0.467 * \star$ & -0.138 & 0.319 \\
\hline Female & $-0.515^{\star \star}$ & $-0.679 \star \star$ & -0.217 & -0.102 \\
\hline
\end{tabular}

* and ** denote significant correlations at $p<0.05$ and $p<0.01$, respectively

Table 5. Results of principal component analysis

\begin{tabular}{clllll}
\hline & \multicolumn{3}{c}{ Male } & \multicolumn{2}{c}{ Female } \\
\hline Component & 1 & 2 & 3 & 1 & 2 \\
\hline $\begin{array}{c}\text { Total } \\
\text { Initial eigenvalues \% of } \\
\text { variance }\end{array}$ & 2.046 & 1.143 & 1.113 & 2.325 & 1.064 \\
\hline Cerebrovascular disease & $\mathbf{0 . 7 8 1}$ & 0.166 & 0.435 & $\mathbf{0 . 8 3 9}$ & -0.030 \\
\hline Heart disease & $\mathbf{0 . 8 6 5}$ & 0.288 & -0.05 & $\mathbf{0 . 8 9 4}$ & -0.317 \\
\hline Cancer & -0.138 & -0.759 & 0.588 & 0.207 & 0.931 \\
\hline Respiratory diseases & -0.28 & 0.51 & 0.759 & 0.276 & 0.307 \\
\hline Nonagenarian ratio & -0.769 & 0.443 & 0.004 & -0.839 & -0.036 \\
\hline
\end{tabular}

Table 6. Latitude of the gravity center and latitude moving southward across different age groups

\begin{tabular}{cccccccccc}
\hline Age (years) & 65 & 70 & 75 & 80 & 85 & 90 & 95 & 100 \\
\hline Latitude $^{\circ} \mathrm{N}$ & 33.70 & 33.55 & 33.31 & 33.03 & 32.73 & 32.28 & 31.26 & 29.62 \\
\hline $\begin{array}{c}\text { Latitude moving } \\
\text { southward }{ }^{\circ} \mathrm{N}\end{array}$ & 0.15 & 0.24 & 0.28 & 0.30 & 0.45 & 1.02 & 1.64 \\
\hline
\end{tabular}

\section{Figures}

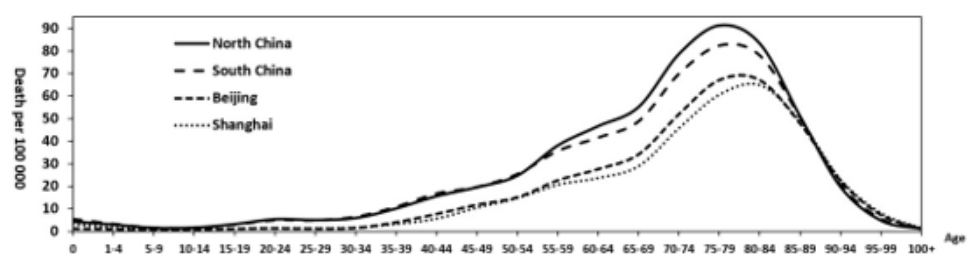

\section{Figure 1}

Difference in age-specific mortality between Beijing and Shanghai under the same age structure

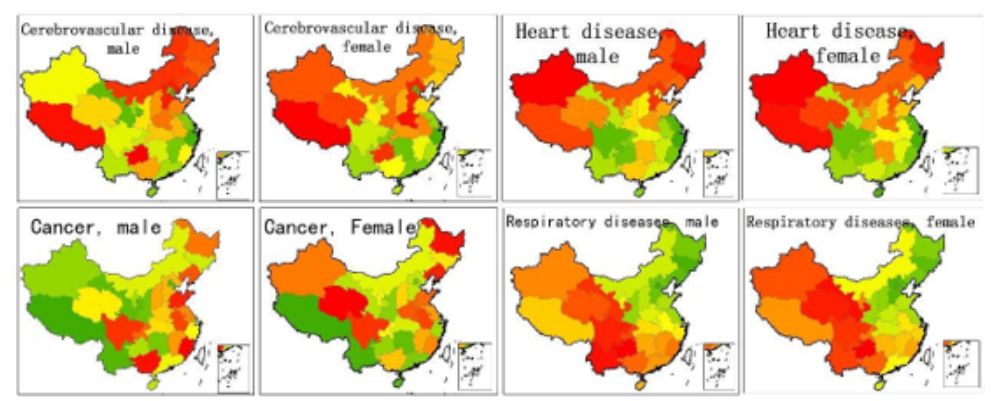

\section{Figure 2}

Distribution of age-standardized mortality rates of four major fatal diseases. Warmer colors indicate higher mortality rate Note: The designations employed and the presentation of the material on this map do not imply the expression of any opinion whatsoever on the part of Research Square concerning the legal 
status of any country, territory, city or area or of its authorities, or concerning the delimitation of its frontiers or boundaries. This map has been provided by the authors.

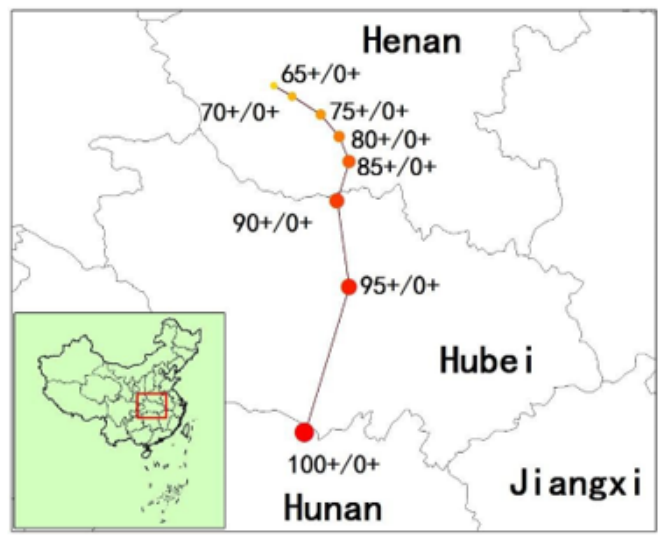

\section{Figure 3}

Evolution map of the gravity centers of longevity indicators in China Note: The designations employed and the presentation of the material on this map do not imply the expression of any opinion whatsoever on the part of Research Square concerning the legal status of any country, territory, city or area or of its authorities, or concerning the delimitation of its frontiers or boundaries. This map has been provided by the authors. 